\title{
EDUCAÇÃO AMBIENTAL, UMA QUESTÃO DE "SOBREVIVÊNCIA": ESTUDO DE CASO PARA O MUNICIPIO DE BOM JESUS/RN
}

\author{
Salatiel Alves da Silva', Carlos Enrique de M. Jerônimo² \\ ${ }^{1}$ UNI-RN - Especialização em Gestão e Perícia Ambiental.( silva.salatiel@bol.com.br ) \\ ${ }^{2}$ Doutorado em Eng. Química. Professor UNI-RN. (c enrique@hotmail.com )
}

\section{RESUMO}

Nos últimos anos, o desenvolvimento tecnológico tem atingido níveis inigualáveis. Como em nenhum outro período da história da humanidade, foram feitas tantas descobertas, em todos os campos da ciência, gerando uma incomparável capacidade de produção. Mas também, é o período em que o ser humano mais produziu meios que podem levá-lo à sua própria destruição. Pois bem, é neste momento, de intensas e desenfreadas degradações, de contaminação do solo, água, ar e uso irracional de recursos naturais que surge uma nova preocupação com a nossa qualidade de vida, a mudança de comportamento das populações interioranas do Brasil no trato com a questão ambiental. Discute-se a ausência dessa população nas práticas de preservação do meio ambiente, o que anteriormente era feito regularmente, alterando as perspectivas de muitos estudiosos e causando estranheza no que se refere a este tipo de comportamento. Destarte, temse como objetivo procurar saber o porquê da intensificação dessas degradações nos últimos anos em sociedades interioranas do Brasil, utilizando-se como amostra o munícipio de Bom Jesus, no estado do Rio Grande do Norte. Seguiu-se um caminho metodológico de observação, visitas a locais degradados, entrevistas, coletas de informação e registro em caderno de anotações. Os resultados apontam para a necessidade do desenvolvimento de um projeto de Educação Ambiental, como fator reparador destas intensas degradações ambientais, em cidades interioranas do Brasil. Bem como, nos conscientizar-mos da gravidade dessa situação em que se encontra o nosso planeta, a fim de que possamos obter os meios necessários para superar essa crise existencial de forma mais sustentável possível, o que se caracteriza, por isso mesmo de ser uma questão de sobrevivência.

Palavras chaves: Autodestruição, Meio ambiente, População interiorana do Brasil, Degradação ambiental, Educação ambiental.

\section{ABSTRACT}

In recent years, technological development has grown enormously and reached unprecedented levels. Like no other time in human history have been so many discoveries in all fields of science, creating an unparalleled production productivity. But also, is the period in which the human being over produced means that can take you to your own destruction. Well, this is time intensive and rampant degradation, soil contamination, water, air and irrational use of natural resources that there's a new concern for our quality of life, change the behavior of populations of Brazil inland tract with environmental issues. It discusses the lack of population in the countryside of Brazil in the practice of environmental conservation, which previously was done regularly, changing the outlook of many scholars and causing strangeness with regard to this type of behavior. Thus, we have aimed to inquire why the intensification of degradation in recent years in corporate interior 
of Brazil, previously taken by many scholars as naturally green, conservative, etc.. There followed a methodological way of observation, visits to places degraded, interviews, collections of information and record in notebook. It is hoped in this way, as a result, we can become aware of the seriousness of the situation that is our planet in order to obtain the necessary means to overcome the existential crisis of a more sustainable way possible, which is characterized by this even be a question of survival. The results point to the need to develop an environmental education project, as a factor of this intense repairing environmental degradation in inner cities of Brazil. As well, we become aware of the seriousness of the situation that is our planet, so that we can find means to overcome the existential crisis of a more sustainable way possible, which is characterized, therefore being a matter of survival.

Keywords: Self-destruction, Environment, Population in the countryside of Brazil, Environmental degradation, Environmental Education.

\section{INTRODUÇÃO}

No mundo atual a tecnologia está presente em tudo, desde o sapato que calçamos até a mais moderna aeronave que utilizamos. Um mundo em que as pessoas não precisam sequer ir à empresa para uma reunião ou participar de uma conferência. Elas podem simplesmente ligar seus computadores e se comunicar em tempo real com som e imagem sem sair de casa. Esta evolução tecnológica pode ser uma grande oportunidade com muitos efeitos positivos, mas também existe seu lado negativo, ela pode ser uma grande ameaça ao seu próprio criador. Ao longo da história, segundo Milton (1999), o homem vem desenvolvendo ferramentas, equipamentos e processos para que ele possa melhor desenvolver suas tarefas, mas esta evolução também surtiu efeitos contrários, como desemprego, pelo analfabetismo tecnológico, diversos problemas econômicos, políticos, sociais e culturais:

A Tecnologia chegou, em nossos tempos, especialmente depois da globalização, a adquirir enorme importância - não só para os indivíduos, mas também, para as nações e para a sociedade em geral - levantando problemas econômicos, políticos, sociais e mesmo culturais. Torna-se, portanto, necessário indagar sobre a própria essência do que é tecnologia. (Milton, 1999)

O homem nunca será inteiramente substituído pela máquina, uma vez que por trás de uma máquina existe a figura de um homem no comando, elas apenas facilitam o trabalho diminuindo a mão de obra. No entanto, enquanto os empregos são extintos outros vários surgem com um requisito básico de um conhecimento técnico mais avançado. Segundo Mônica (2007), esses avanços tecnológicos nem sempre tem os seus objetivos alcançados, principalmente pela forma como são aplicados:

O desenvolvimento de novas tecnologias inventadas e reinventadas pelo homem deve vir acompanhado de uma evolução sistemática de suas irreversibilidades, condicionamentos e possibilidades nem todas aproveitadas, pois o resultado da tecnologia depende da forma como ela é aplicada. (Monica, 2007)

Quando falamos de desenvolvimento tecnológico, devemos falar também de Ecologia, pois não podemos esquecer-nos do meio ambiente em que esse desenvolvimento vai ser aplicado. Por outro lado, quando definimos a palavra "Ecologia" dizemos que é a ciência que estuda a relação entre os seres vivos e o estudo da relação destes com o meio ambiente. Ora, a palavra "Ecologia" 
tem sua origem no grego, cuja significação se faz pela junção de dois termos: Oikos = Casa + Logia = ciência, tratado, estudo. Resultando, portanto, a significação dos dois termos como "estudo da casa", considerando, por certo, o meio ambiente como a nossa casa, casa essa que vivemos e que precisamos cuidar bem. Wikipédia (2012).

A palavra Ecologia tem origem no grego Oikos, que significa casa, e Logos, estudo, logo, por extensão seria o estudo da casa, ou, de forma mais genérica, do lugar onde se vive. Wikipédia (2012).

Esta oikos usada com racionalidade, com sustentabilidade, pois se é a casa que vivemos e que dela dependemos para encontrarmos os elementos essenciais para a nossa sobrevivência, por que não cuidar desta? Por outro lado, essa casa que moramos (o meio ambiente), composta de solo, água, ar, vegetação, animais, homem, ecossistema, fenômenos físicos, químicos, biológicos e antrópicos, caso não seja bem cuidada, usada com racionalidade, com Educação Ambiental, pensando no próximo e no equilíbrio dos ecossistemas, por certo estará fadada à destruição.

Esta destruição, a nível ambiental conhecida como "degradação ambiental", não afetará apenas o equilíbrio dos sistemas existentes, como também, todos os elementos componentes do meio ambiente, já citados anteriormente. Colocará, com certeza, em risco toda existência de vida do nosso Planeta, conforme descreve Silva (1998):

Desde o princípio de sua história o homem tem exercido intensa atividade sobre a natureza, extraindo suas riquezas florestais, pampas e, em menor intensidade, as montanhas. [...] Essa ocupação tem sido realizada sem um planejamento ambiental adequado causando alterações significativas nos ecossistemas do planeta. As queimadas, geralmente praticadas pelo homem, são atualmente um dos principais fatores que contribuem para a redução da floresta em todo o mundo, além de aumentar a concentração de dióxido de carbono na atmosfera, agravando o aquecimento do planeta (SILVA, 1998).

Segundo DIAS (2011), entrementes, a continuação desse processo de autodestruição está em curso, cada vez mais crescente, inúmeras são as denúncias de impactos ambientais, é o homem contaminando o meio ambiente e realizando degradação ambiental sem fronteiras, em rítmo acelerado, desde a Revolução Industrial.

No entanto, também é o período histórico em que o ser humano gerou os meios que podem levá-lo à extinção. O homem, sem predadores naturais, torna-se, como afirmava Thomas Hobbes, o lobo de si mesmo. O processo que ora está em curso, de contaminação excessiva do meio ambiente natural, foi acelerado com a Revolução Industrial e sua compreensão é fundamental para que nos conscientizemos da gravidade da situação e para a obtenção dos meios necessários para a sua superação. DIAS (2011).

Pois bem, é neste momento, de intensas e desenfreadas degradações, de contaminação do solo, água, ar e uso irracional de recursos naturais que surge uma nova preocupação com a nossa qualidade de vida, a mudança de comportamento das populações interioranas do Brasil no trato com a questão ambiental.

Segundo Berna (2001), o meio ambiente é destruído também e principalmente, devido ao atual estágio de desenvolvimento existente nas relações sociais de nossa espécie. Essa degradação ambiental reflete-se diretamente na perda de qualidade de vida, como: moradias inadequadas, 
poluições generalizadas, em todas suas dimensões, destruição de habitats naturais, intervenções desastrosas nos mecanismos que sustentam a vida na terra.

Dessa forma, através de uma visão técnica e cultural, o presente trabalho vem apontar a ausência da população interiorana do Brasil nas práticas de preservação do meio ambiente, o que anteriormente era feito regularmente, alterando as perspectivas de muitos estudiosos e causando estranheza no que se refere a este tipo de comportamento.

Procura-se objetivar, então, através deste, saber o porquê da intensificação dessas degradações nos últimos anos em sociedades interioranas do Brasil, anteriormente tidas por muitos estudiosos como naturalmente ecológicas, conservadoras, etc. A partir daí, espera-se encontrar a resposta para o questionamento do artigo. Como também, espera-se que através deste possamos nos conscientizar da gravidade dessa situação em que se encontra o nosso planeta, a fim de obtermos os meios necessários para superar essa crise existencial de forma mais sustentável possível.

\section{MATERIAL E MÉTODOS}

\section{Metodologia}

Seguindo uma metodologia de observação e visitas a locais degradados, entrevistas, coleta de informação e registro em caderno de anotações, realizou-se uma pesquisa por amostragem, entrevistou-se cinquenta moradores, procurando-se investigar o porquê da intensificação de degradações ambientais nos últimos anos em cidades interioranas do Brasil, anteriormente tidas como conservadoras, naturalmente ecológicas e comprometidas com o meio ambiente. A metodologia ora aplicada partiu de iniciativa do próprio autor do artigo, conhecedor da história, costumes e comportamentos daquele povo. Sendo, portanto, o trabalho, e bem como os seus objetivos, pioneiros naquela pacata cidade interiorana denominada Bom Jesus.

Para viabilizar a realização dessa pesquisa, ateve-se apenas a pesquisar o município de Bom Jesus/RN, distante $46 \mathrm{~km}$ da capital Natal e a realizar visitas e observação em outros municípios vizinhos, como Senador Elói de Souza, Boa Saúde, Serra Caiada, etc. Tentou-se aproximar ao máximo da realidade social dessas populações, buscando as causas da mudança de comportamento e a compreensão dos efeitos dessa realidade para a construção deste trabalho.

Por oportuno, a partir daí, procurou-se evidenciar a realidade dos problemas sócioambientais, fenômenos estes que fazem parte do dia-a-dia da população. Com isto, identificaramse as dificuldades dessas populações para sobreviver em um espaço que muitas vezes se apresenta hostil, carente e desprezado pelo Poder Público.

\section{Espaço Amostral}

A cidade de Bom Jesus pode ser contado através do texto, constante do IDEMA, Bom Jesus (2007), o qual exprime sobremaneira suas raízes históricas, constituição espacial e desmembramento das regiões da qual fazia parte, como de um verdadeiro conglomerado geográfico, conforme abaixo descrito: 
Com a doação de sesmaria ao padre José Vieira Afonso, em 1754, na qual estava incluída a posse ao redor de toda lagoa da Panela, começou uma povoação voltada para a criação de gado e cultivo de lavouras. Em 1820, o povoado apresentava sinais de crescimento e seus direitos de posse foram dados ao Sr. Felix do Rego Barros e lagoa da Panela passou a se chamar Capoeiras, só voltando ao seu nome original depois de muitos anos. Segundo Ferreira Nobre, no ano de 1877, Panelas era um povoado com policiamento e feira. A comunidade permaneceu com o nome Panelas até o dia 10 de novembro de 1936, quando por força de Lei Estadual no 31, seu nome foi mudado para Bom Jesus. No dia 11 de maio de 1962, através da Lei no 2.794, Bom Jesus desmembrou-se de Senador Elói de Souza e tornou-se um novo município do Rio Grande do Norte. IDEMA (2007).

A cidade de Bom Jesus, localizada no interior do Estado Norte-rio-grandense, distante 46 quilômetros de Natal, capital do Estado, possui aproximadamente 8.608 habitantes; Integra a mesorregião do Agreste Potiguar, apresentando as seguintes características fisiográficas: área de $122,03 \mathrm{~km}^{2}$; clima com características muito quente e semi-árido, com precipitações pluviométricas anuais $850,5 \mathrm{~mm}$; vegetação caatinga hipoxerófila, vegetação de clima semi-árido, apresenta arbustos e árvores com espinhos e de aspecto menos agressivo do que a caatinga hipoxerófila; com características de transição entre a litorânea e a caatinga; solos predominantes: Podzólico Vermelho Amarelo Abrúptico Plíntico - fertilidade natural baixa, textura média, relevo plano, imperfeitamente drenado, profundo (IDEMA, 2007; IBGE, 2011).

A cidade de Bom Jesus é cheia de contrastes, enquanto que uma boa parte de sua população se mostra humilde, simples, carente, outra parte, tem uma vida mais abastarda. Por isso, acredita-se que a Educação Ambiental poderá contribuir para a formação de cidadãos, de pessoas comprometidas com a vida e com o bem-estar de cada um na sociedade, como cita Zacarias (2000):

[...] a partir de um enfoque crítico, a Educação Ambiental poderá contribuir para a formação de cidadãos conscientes, aptos para se decidirem a atuar na realidade socioambiental de um modo comprometido com a vida, com o bem-estar de cada um e da sociedade local e global (Zacarias, 2000).

\section{Questionário}

O questionário adotado pela pesquisa realizada na cidade, por amostragem, em um universo de cinquenta pessoas, seguiu-se conforme o modelo de questionário abaixo, que embora de aparência simples, nos trouxe informações bastante enriquecedoras e contextualizadas, pois traçou-nos um perfil cultural, econômico e social da população, informações essas muitas vezes ocultas na esfera social de cada elemento participante.

\section{QUESTIONÁRIO}

1) Qual o seu nível de escolaridade?

2) Você tem alguma profissão?

3) Você trabalha na agricultura? 
4) Quantos salários mínimos você recebe decorrente do seu trabalho?

5) Quantas pessoas moram com você?

6) Qual a sua religião?

7) Você sabe o que é Educação Ambiental?

8) Você cuida do meio ambiente?

\section{RESULTADOS E DISCUSSÕES}

De acordo com a pesquisa realizada, por amostragem, constatou-se que a população de Bom Jesus é constituída, basicamente, por pessoas com características simples e de baixo poder aquisitivo, alguns com pouca ou sem nenhuma instrução, enquanto que outro seguimento, destoando desse perfil, é constituído por pessoas com cursos superiores completos, professores graduados, profissionais especializados, etc.

Há também outro seguimento, com curso médio e outro apenas com ensino fundamental. Os resultados constantes da Figura 1 nos revelaram as seguintes informações: 1) As maiorias dos pais de família têm como atividade econômica a agricultura; 2) Possuem uma renda mínima entre 1 e 2 salários mínimos; 3) A maioria dos pais não são alfabetizados; 4) As famílias têm em média entre 4 e 5 membros, embora haja casos em que os números extrapolam essa quantidade; e 5) A religião predominante entre essas famílias é o Catolicismo.

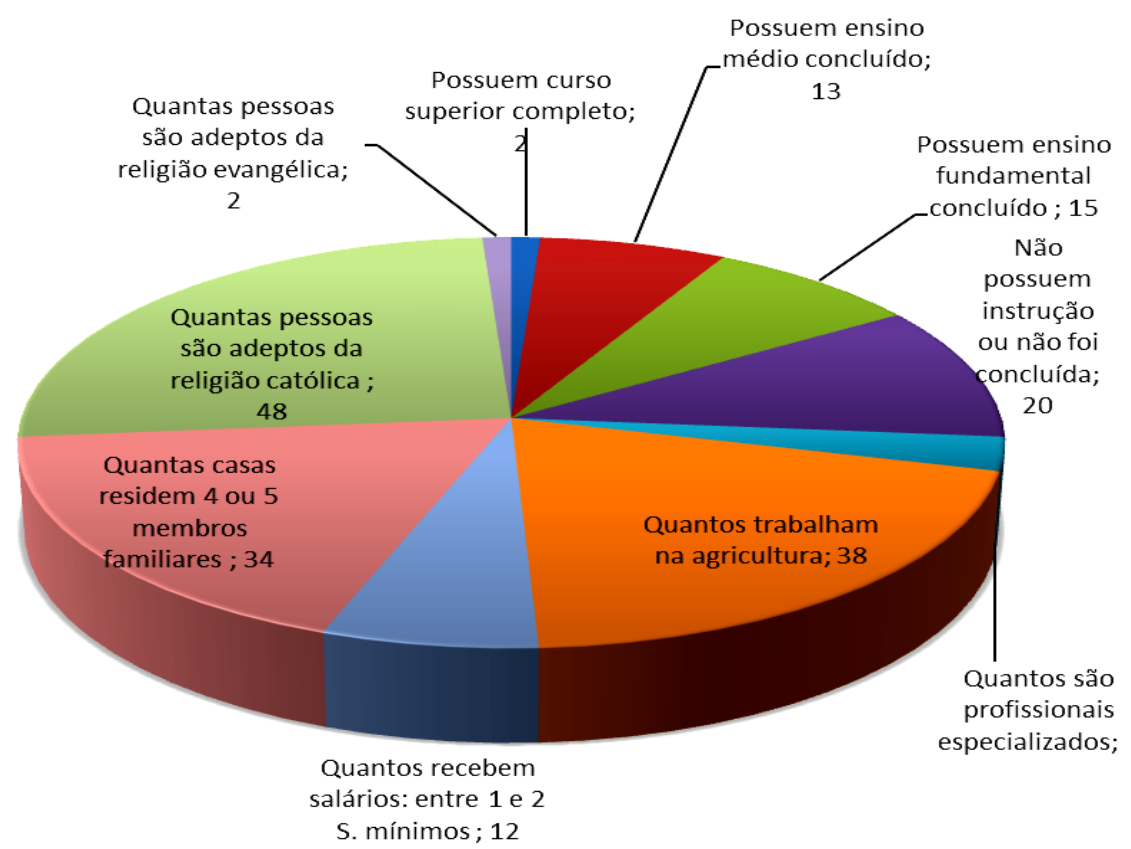

Figura 1. Dados obtidos com aplicação dos questionários.

Assim, através desses dados que serviu de amostragem da população bonjesusense, pôdese traçar um perfil sócio-econômico dessa população, que revela um poder aquisitivo que pode ser avaliado entre baixo e médio. Sem muitas opções, a maioria dessas famílias reside em casas 
humildes, e apresentam um vestuário simples, portanto, não ostentam peças caras de roupas de grife ou quaisquer tipos de riquezas.

Muitas famílias diante do contexto de que vivem, de residirem em áreas inóspitas, nos sítios, em uma área rural, além dessas dificuldades que têm esses alunos que vivem nessas áreas, quer seja no deslocamento dos sítios até a escola, ou da sua própria subsistência, encontram também dificuldades para dividir sua atenção entre a escola e o trabalho na agricultura, do qual depende toda sua família, onde muitos terminam por optar pelo trabalho.

Os resultados da pesquisa constantes da Tabela 1 nos revelam que a maioria dos moradores desconhecem o que quer dizer Educação Ambiental no real sentido da palavra, apenas têm uma vaga noção. Como também, que não se mostram interessados em saber, uma vez que sua situação social e o descaso praticado pelo poder público, os conduziram à inércia da questão ambiental.

Tabela 1. Dados obtidos com aplicação dos questionários.

\begin{tabular}{|c|c|c|c|}
\hline Você cuida do meio ambiente? & Resp. & Você sabe o que é Educação Ambiental? & Resp. \\
\hline Não, é função do governo. & 23 & Sim, é cuidar do lugar. & 11 \\
\hline Sim, cuido & 16 & Não sabem & 27 \\
\hline Às vezes & Oito & Tem ligeira noção & Nove \\
\hline Não quiseram responder & Três & Não quiseram responder & Três \\
\hline Total & 50 & Total & 50 \\
\hline
\end{tabular}

Embora as perguntas sejam simples, o resultado foi recompensador, trazendo informações inéditas. As respostas e informações trouxeram para o momento da análise, um quadro revelador de insatisfação dessa população, desprezada pelo poder público, de não atendimento de suas necessidades sociais, do sentimento de perda de identidade em relação ao espaço em que vivem, por não terem mais compromisso com aquele espaço.

Para estes moradores, tudo que está fora de suas casas pertence ao governo e é ele (o governo) quem deveria cuidar. Como a máquina pública deixa muito a desejar em seus serviços municipais, fica então o quadro de completo descaso, sob a justificativa desse segmento populacional para não se importarem com as questões ambientais. Com as respostas da pesquisa e de informações obtidas dos moradores, montou-se outro quadro, agora o de crise social vivenciada por essa população, onde são manifestados argumentos que embora não justifiquem a sua condição social ou econômica, mas que procuram explicar os motivos que levaram à sua mudança de comportamento. Esse cenário é apresentado na Tabela 2.

Tabela 2. Cenários observados.

\begin{tabular}{|cl|}
\hline Quadro de Crise Social da População de Bom Jesus \\
\hline 1- & Descaso do Poder Público \\
\hline 2- & Pobreza, Miséria \\
\hline 3- & Sentimento de Perda de Identidade Social \\
\hline 4- & Descompromisso com o espaço em que vivem \\
\hline 5- & Desinteresse com o Meio Ambiente \\
\hline
\end{tabular}

É importante salientar que este quadro social se repete em outros municípios do Interior do Rio Grande do Norte, como Elói de Souza, Boa Saúde, Serra Caiada, etc., onde foi encontrado quadro social semelhante. Apesar do progresso econômico, técnico científico e de diversas campanhas de conscientização, sobre o desenvolvimento sustentável, tem sido constatado que os 
problemas ambientais têm aumentado muito nos últimos anos, conforme cita Novais (2008) em seu artigo "Opulência e Pobreza":

O que se verifica de forma clara nessas matérias é que esses cenários representam a degradação social e ambiental: a riqueza e a pobreza, a opulência e a miséria. Considere-se que estamos comentando sobre casos de um país rico em recursos naturais como o Brasil. Dessa forma, percebese que apesar do "progresso", da maior conscientização das pessoas e da pesquisa ter evoluído significativamente nos últimos tempos, os problemas sociais e ambientais vêm se agravando de forma considerável. Esse fato se deve, em grande parte, a ausência de princípios éticos e ao individualismo de atitudes que o modelo de desenvolvimento e produção gerou. (NOVAIS, 2008).

Essas degradações passam despercebidas aos olhos dos detentores do poder público, e podem ser correlacionadas com a opinião popular acerca do assunto em questão, conforme Tabela 3.

Tabela 3. Correlação entre os principais impactos ambientais e o comentário dos populares.

\begin{tabular}{|l|l|}
\hline DEGRADAÇÃO & COMENTÁRIO \\
\hline Pouco saneamento básico & Há ruas com valas para escoamento dos esgotos das casas. \\
\hline $\begin{array}{l}\text { Constantes queimadas de entulhos } \\
\text { nas ruas }\end{array}$ & $\begin{array}{l}\text { Os entulhos das ruas são amontoados e depois queimados pela própria } \\
\text { população. }\end{array}$ \\
\hline Não há coleta seletiva de lixo & O lixo é recolhido de forma precária. \\
\hline Pouco abastecimento de água & O abastecimento da água encanada é feito de forma precária. \\
\hline Alto índice de analfabetismo & $\begin{array}{l}\text { Poucos conseguem concluir os seus estudos, pois o tempo fica dividido entre } \\
\text { trabalhar na agricultura ou estudar. }\end{array}$ \\
\hline Alto índice de violência & Assaltos ao comércio, envolvimento de jovens e adolescentes com drogas. \\
\hline Alto índice de problemas sociais & $\begin{array}{l}\text { Casos de gravidez em menores adolescentes, pedofilia, etc. O conselho } \\
\text { tutelar é ineficiente. }\end{array}$ \\
\hline Carente assistência-médico-hospitalar & $\begin{array}{l}\text { Falta de equipamentos, médicos especializados e a falta de uma melhor } \\
\text { assistência médica, alto número de óbitos na cidade. }\end{array}$ \\
\hline
\end{tabular}

A partir das informações apresentadas no quadro anterior sobre as degradações sócio-ambientais existentes na cidade de Bom Jesus/RN, foram feitos registros fotográficos de algumas das suas ruas, as quais podem revelar o desleixo e o desinteresse do poder público da cidade para com os problemas sócio-ambientais da cidade, deixando a sua população sem opção e desassistida. Conforme as fotos a seguir revelam, não há saneamento básico na cidade e a maioria das ruas apresenta um aspecto degradante de valas a céu aberto. Contribuindo, dessa forma, para que além da péssima paisagem das ruas, a existência do mau cheiro das águas das valas e o constante risco da contaminação das pessoas, decorrente da proliferação das doenças infectocontagiosas. 


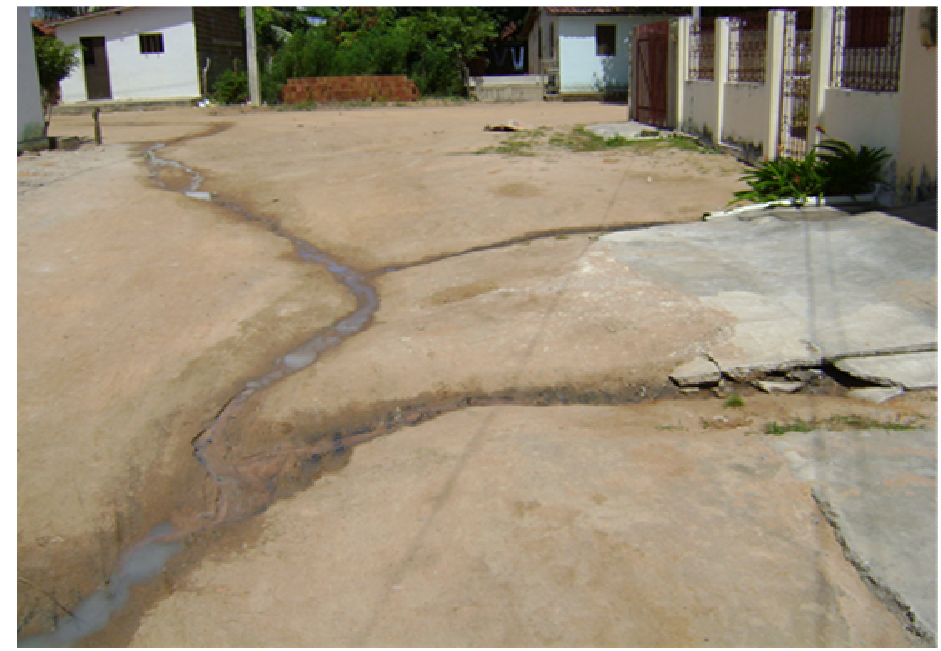

Figura 2. Valas a céu aberto. Fonte: Fotografia produzida pelo autor exclusivamente para este trabalho.

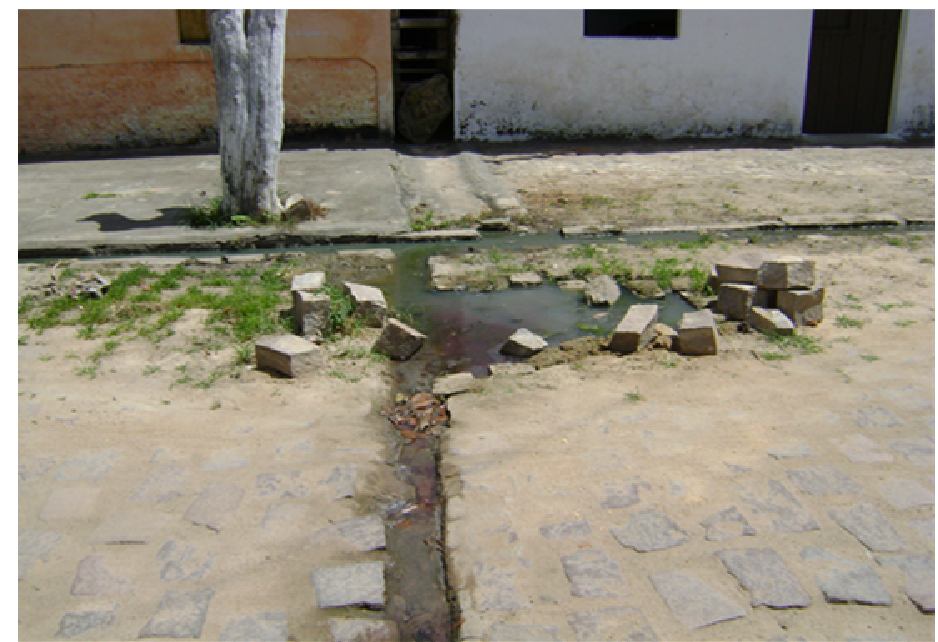

Figura 2. Esgotos em valas nas ruas. Fonte: Fotografia produzida pelo autor exclusivamente para este trabal ho.

Como podemos ver através das fotos anteriores, que os esgotos encontram-se a céu aberto, as águas correm por meio de valas. Por isso, Meireles (2001) acrescenta que poucos são os esgotos domésticos que são tratados no Brasil, sendo a maioria despejados em cursos de água:

Sobre o lixo decorrente de podas e limpeza das casas, este é jogado nas ruas, manchando então a paisagem da cidade, conforme Cozetti (2001). 


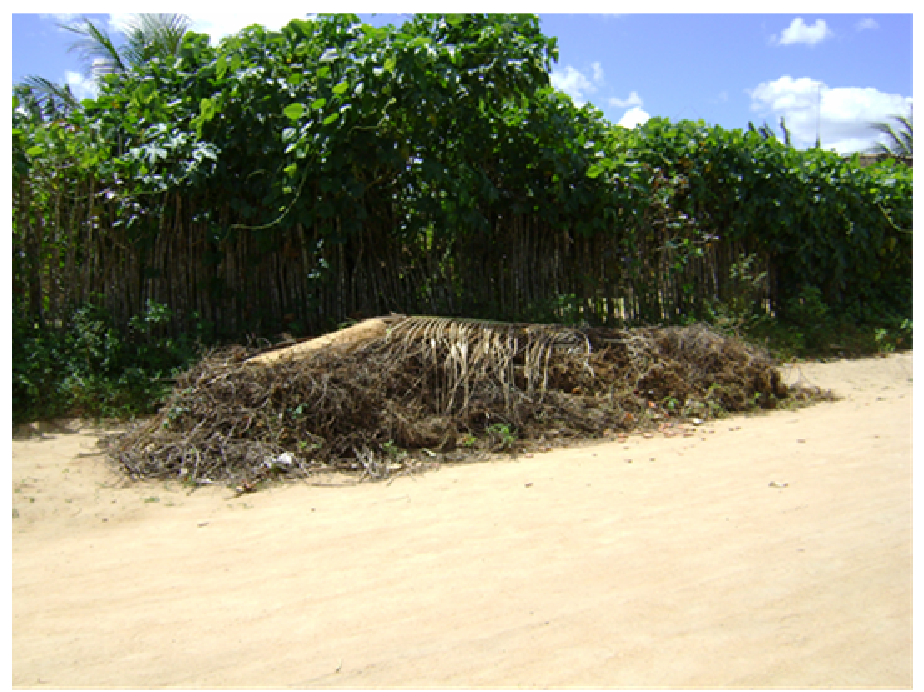

Figura 3. Lixo ao lado da cerca de uma residência

Fonte. Fotografia produzida pelo autor exclusivamente para este trabalho.

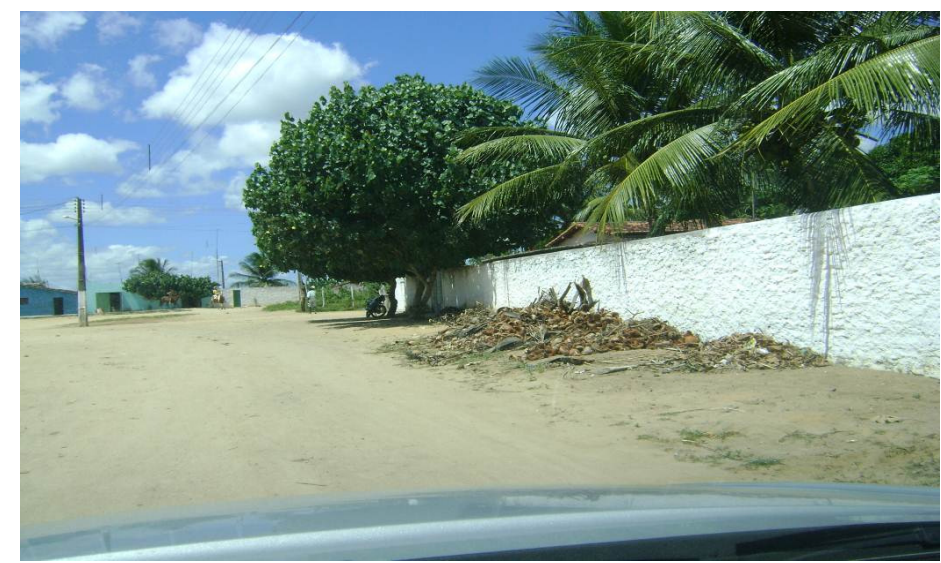

Figura 4. Entulhos jogados na rua.

Fonte. Fotografia produzida pelo autor para esta pesquisa.

\section{Educação Ambiental uma Questão de "Sobrevivência"}

Buscando uma melhor forma para compreensão do título desse artigo, julgou-se necessário, tecer algumas explicações à cerca da terminologia sobrevivência. Desde a sua origem o homem vem procurando superar as dificuldades para satisfazer as suas necessidades básicas, como alimentação, moradia, etc., enfrentando perigos e desafios, etc., sempre praticando atos sociais em relação ao meio ambiente. Partindo do pressuposto de que a ação praticada pelo homem seja uma ação social, e de que as degradações ambientais são prejuízos trazidos ao meio ambiente, meio ambiente este que abastece ao homem de todos os recursos necessários para a sua sobrevivência, têm-se que, as degradações ambientais, são prejuízos trazidos ao meio ambiente pelo próprio homem, em sua relação diária com o meio, que o torna na verdade um agente ativo e passivo ao mesmo tempo, colocando em risco a sua própria existência. Daí a justificativa do termo sobrevivência, que revela a degradação ambiental como produto e um fenômeno antrópico, resultante de ações muitas vezes desenfreadas, na busca das satisfações das 
necessidades humanas. Apesar do progresso econômico, técnico científico e de diversas campanhas de conscientização, sobre o desenvolvimento sustentável, tem sido constatado que os problemas ambientais têm aumentado muito nos últimos anos. Vejamos o que diz Novais (2008) em seu artigo "Opulência e Pobreza:

O que se verifica de forma clara nessas matérias é que esses cenários representam a degradação social e ambiental: a riqueza e a pobreza, a opulência e a miséria. Considerese que estamos comentando sobre casos de um país rico em recursos naturais como o Brasil. Dessa forma, percebe-se que apesar do "progresso", da maior conscientização das pessoas e da pesquisa ter evoluído significativamente nos últimos tempos, os problemas sociais e ambientais vêm se agravando de forma considerável. Esse fato se deve, em grande parte, a ausência de princípios éticos e ao individualismo de atitudes que o modelo de desenvolvimento e produção gerou. (NOVAIS, 2008).

Um solo bem cuidado favorecerá a prática de uma lavoura eficiente, preservará os recursos naturais existentes, renderá bons frutos para aqueles que assim procederem e proporcionará uma melhoria na qualidade de vida para todos. De outra forma, não haverá solo apropriado, não haverá trabalho frutífero e não poderá ser cultivado apropriadamente. Devemos, pois, viver de forma civilizada e solidária com a terra, como Morin (2000) nos diz:

Estamos comprometidos, na escala da humanidade planetária, na obra essencial da vida, que é resistir à morte. Civilizar e solidarizar a terra, transformar a espécie humana em verdadeira humanidade torna-se o objetivo fundamental e global de toda educação que aspira não apenas ao progresso, mas à sobrevida da humanidade. A consciência de nossa humanidade nesta era planetária deveria conduzir-nos à solidariedade e à comiseração recíproca, de indivíduo para indivíduo, de todos para todos. A educação do futuro deverá ensinar a ética da compreensão planetária (MORIN, 2000).

A água que bebemos, ou que usamos na lavoura, ou em outras necessidades, também quando bem cuidada, desde seu processo de purificação nas estações de tratamento, é fonte de vida, necessária a todo organismo vivo na face da terra.

Não incluindo aqui, os milhares de outras utilizações que fazemos dela no nosso dia-a-dia, como asseio corporal, etc. Como também, o ar que respiramos, essencial também a todos os animais e vegetais, precisa ser bem cuidado, pois sem ele não existiríamos. Esse ar é o mesmo que muitas vezes contemplamos manchado no céu por elementos poluidores e outras substâncias diversas, encontrados nas chaminés das fábricas, nas descargas dos automóveis ou nas grandes queimadas, etc. Depois de poluído, ele é causador de diversas doenças pulmonares e, mais ainda, nos mostram que a sua contaminação é resultante de atos irresponsáveis e de gananciosos econômicos que buscam, mesmo em de detrimento de outros, tirar qualquer vantagem, apesar de tudo. Mas, o grande problema é que as pessoas sempre esperam que esse mundo se torne melhor por ele próprio ou começando a partir de outrem. Acham que é mais fácil reclamar, afirmando que ninguém faz nada, que a culpa é do "Sistema", dos governantes, dos empresários, etc. Mas, o que na verdade está faltando é a formação de cidadãos conscientes, comprometidos com a vida, como nos diz Zacarias (2000):

[...] a partir de um enfoque crítico, a Educação Ambiental poderá contribuir para a formação de cidadãos conscientes, aptos para se decidirem a atuar na realidade 
socioambiental de um modo comprometido com a vida, com o bem-estar de cada um e da sociedade local e global. (ZACARIAS, 2000).

Dessa forma, cidadãos sensibilizados e conscientes, estarão capacitados para agir e atuar no meio em que vivem de forma coletiva e responsável.

Na Educação Ambiental, o importante é que a ação comece em nós, ou a partir de nós, que tenhamos o compromisso de sermos melhores constantemente. O que precisamos todos nós humanos entender é que de nada adianta recebermos toda a fortuna do mundo, obter toda a justiça social que necessitemos para resolver os nossos problemas, e permanecermos inertes, sem se preocupar com o planeta em que nós vivemos e este venha tornar-se sem capacidade de sustentar a vida humana com qualidade. As lutas ambientais são também ações emancipadoras, educativas e em busca de uma sociedade mais justa e sustentável, como nos diz Carvalho (2004):

Assim, as lutas ambientais são espaços de ação emancipadores que devem ser valorizados por uma prática educativa que se some à busca de uma sociedade justa e ambientalmente sustentável. Nesse sentido, a Educação Ambiental estaria ao lado das forças integrantes de um projeto de cidadania democrática, ampliada pela idéia de justiça ambiental. Justiça ambiental, no caso, significa a responsabilidade de todos na preservação dos bens ambientais e a garantia de seu caráter coletivo. Esse tem sido um dos novos conceitos utilizados na luta ambiental, evidenciando a distribuição desigual do acesso aos bens ambientais e de seu uso e a precariedade dos padrões de qualidade de vida a que têm sido submetidas às populações mais pobres do planeta. Ao destacar a dimensão ambiental das lutas sociais e apoiar as ações prol da justiça no acesso aos bens ambientais e no uso desses bens, a Educação Ambiental crítica está contribuindo para a ampliação da noção de cidadania e justiça social (Carvalho, 2004)

A falta de conhecimento e a falta de consciência ambiental, depois dos problemas sociais, são os grandes responsáveis pelas degradações ambientais. Precisamos entender também, que a causa da degradação dos recursos naturais não é resultante diretamente da forma como a nós nos relacionamos com o planeta terra, mas sim e principalmente pelo modo como nós nos relacionamos consigo mesmos. Uma vez que a relação da nossa espécie com o planeta é resultante de tudo aquilo que aprendemos com os nossos pais, com a cultura do nosso povo. Berna (2001) cita sobre essa questão da relação do homem com o meio ambiente:

A destruição da natureza não resulta da forma como nossa espécie se relaciona com o planeta, mas da maneira como se consigo mesma. Ao desmatar, queimar, poluir, utilizar ou desperdiçar recursos naturais ou energéticos, cada ser humano está reproduzindo o que aprendeu ao longo da história e da cultura de seu povo. Portanto, a ação destruidora não é um ato isolado de um ou outro indivíduo, mas reflete as relações culturais, sociais e tecnológicas de sua sociedade (Berna, 2001)

Ao se desmatar, fazer queimadas, poluir, desperdiçar os recursos naturais, etc., cada um de nós estamos reproduzindo o que aprendemos ao longo da nossa existência, através da cultura do nosso povo. A ação destruidora do homem não é um ato isolado, ela é reflexo de relações culturais, sociais, etc. Daí, portanto, torna-se impossível que pessoas que foram exploradas, injustiçadas e impedidos dos seus direitos de cidadãos, que compreendam que não devem explorar os outros seres vivos. Conforme Berna (2001) nos explica:

[...] Então, é impossível pretender que seres humanos explorados, injustiçados e desprovidos de seus direitos de cidadãos consigam compreender que não devem explorar 
outros seres vivos, como animais e plantas, considerados inferiores pelos humanos (Berna, 2001).

Compreende-se então, que a nossa atual relação com a natureza é apenas um reflexo das relações humanas entre nós mesmos. Se nós vivemos sendo explorados, com certeza achamos natural explorar os outros seres também. Acredita-se também, que não há Educação Ambiental sem participação política, uma vez que o ensino sobre o meio ambiente deve contribuir principalmente para o exercício da cidadania, estimulando a ação transformadora entre as pessoas e buscando melhores tecnologias voltadas para a preservação ambiental, como estimular a mudança de comportamentos e a construção de novos valores éticos menos antropocêntricos. Mas, não adianta o homem se tornar apenas mais consciente dos problemas ambientais, resultantes das suas relações com o meio, sem se tornar também mais ativo, participativo. Isto quer dizer que o comportamento dos cidadãos em relação ao seu meio ambiente é indissociável do exercício da cidadania, como também que a Educação Ambiental é um ato político, baseado em valores sociais.

Dessa forma, podemos compreender a Educação Ambiental como um processo de aprendizagem permanente, baseado no respeito a todas as formas de vida, tendo o firme propósito de formar cidadãos com consciência local e planetária de respeito ao meio ambiente, despertando novos valores e incentivando para que as pessoas tenham uma qualidade de vida melhor, mais adequada, objetivando a sua própria sobrevivência.

Diante de descasos com o meio ambiente, é de suma importância que todos se unam para que providências sejam tomadas no sentido de pressionar e fazer com que a máquina administrativa dos municípios façam cumprir suas obrigações e os seus serviços junto à comunidades e que cada um se conscientize da necessidade de cuidar do espaço em que vive. Para a população, principalmente a mais carente, as questões ecológicas estão associadas ao combate a poluição, coleta de lixo, agrotóxicos, desmatamentos, segurança, moradia, etc. E deve ter a adoção de uma política ambiental mais eficiente, com leis rigorosas e monitoramento ambiental permanente.

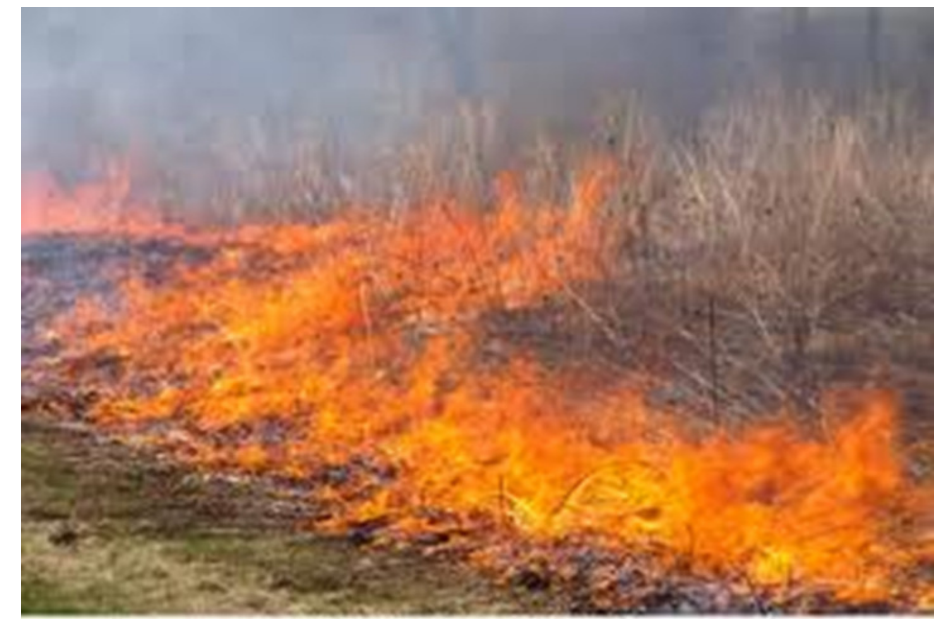

Figura 5. Queimadas praticadas por proprietários de terras Fonte. Edylon Fotos - Blog 100\% Bom Jesus

A Educação Ambiental, com certeza irá despertar a cidadania existente em cada pessoa, principalmente em sua comunidade, despertando sua consciência ecológica, e irão estimular o 
pensamento crítico e despertar novos valores, fatores essenciais para a convivência na coletividade.

\title{
Os Novos Comportamentos das Sociedades Interioranas
}

Muitos estudiosos comungam da mesma opinião de que a degradação ambiental é mais intensa nas grandes cidades. Mas, não podemos esquecer também de que há o processo de alienação cultural, inclusive citado por Berna (2001), pela perda da identidade ou por não tê-la com o lugar, não dando a menor importância para as questões ambientais, uma vez que não pertence a este, mais intensamente nas periferias das grandes cidades do que em outro lugar. Isto porque há um grande contingente de trabalhadores que abandonaram seus lugares, vindos muitas vezes do interior, em busca de trabalho e passaram a residir na periferia dos grandes centros, não dando qualquer importância ao espaço que utilizam apenas para dormir. Acreditando que as cidades interioranas, já estejam naturalmente comprometidas com o meio ambiente. Acontece é que, como tudo que existem, os comportamentos, as pessoas e as suas atitudes muda, ou por um motivo ou por outro.

A Educação Ambiental entre as cidades interioranas parece estar esquecida ou nunca havia existido, algo que em tempos passados já foi uma característica natural, o cuidar, o limpar a frente de suas residências, o comportamento ecológico dessas populações. Mas, uma pergunta surge neste momento de intensas transformações: Por que o comportamento destas populações mudou? Por que suas atitudes deixaram de ser ecológicas? Entendemos por Educação Ambiental defender a natureza, a fauna, a flora, zelar pelo meio ambiente, preservar os ecossistemas e os habitats, combater a degradação dos recursos naturais, a poluição, a contaminação do lençol freático, etc., ou seja, pensar em sustentabilidade como um todo, observando leis ambientais existentes e muitas vezes não cumpridas. Sobre esse cuidado com os animais e a preservação ambiental como um todo nos diz Vininha (2004), diretora de Ecoturismo, Jornalista e Ambientalista, em seu artigo:

\begin{abstract}
Algumas leis foram criadas para defender os animais, mas ainda não estão sendo cumpridas, por isto o ideal é que nós busquemos implantar maneiras de impedir que ocorram certas atitudes reprováveis. Nas áreas sob propriedade privada, cabe ao proprietário estabelecer as condições para pesquisa e visitação pelo público, observadas as exigências e restrições legais. Cabe a nós, indivíduos, fazer do ecoturismo uma ferramenta para o despertar responsável de cada um, transformando-se num instrumento capaz de reafirmar o papel do indivíduo no mundo, se preocupando com a sustentabilidade, com a educação ambiental e com a inclusão social. Precisamos desenvolver 'códigos de conduta' voluntários, a fim de controlar os impactos ambientais e sociais de funcionários e clientes, e assegurar que o cumprimento destes códigos seja monitorado adequadamente (Vininha, 2004).
\end{abstract}

A Educação Ambiental está associada intimamente à cultura. Por que muitas vezes as pessoas se preocupam tão pouco com as questões ambientais? Uma das principais causas desse fenômeno é a perda de identidade cultural de grande parte da população. Sem identidade cultural não importa muito saber que o patrimônio de uma sociedade, seja ambiental, histórico, cultural, etc., esteja sendo ameaçado ou destruído. À medida que as pessoas não se sentem donos destes 
espaços, esses espaços passam a serem considerada terra de ninguém, ou como pertencentes aos governos.

Dessa forma, não há nenhum sentimento de perda quando um espaço deixa de existir, quando um lago ou um manguezal é aterrado, por não ter identidade cultural, a população também não se sente parte dele. Ou seja, o descaso, a miséria e a pobreza também contribuem para a sensação de perda de identidade cultural, o homem não se sente parte do lugar em que vive, considerando como tudo pertencente ao governo. A pobreza não justifica o fato das degradações existirem, mas o descaso e a falta de assistência social a essas populações, com certeza irá despertar reciprocamente uma atitude desinteressada com as causas ambientais, motivada pelo descaso. As periferias das grandes cidades e as cidades interioranas onde o descaso social e a miséria imperam, são espaços onde mais se repetem este fenômeno de desinteresse pelas causas ambientais. Sobre esse fato Berna (2001) nos diz:

É fato que, por mais carente que seja, a população possui consciência ecológica, só que essa percepção é bastante romântica, associando-se mais à proteção de plantas e animais e menos à qualidade de vida da espécie humana, como se não fizéssemos parte da natureza. Para a maioria, lutar pelo fim das valas de esgotos a céu aberto, más condições de trabalho nas fábricas não tem nada a ver com meio ambiente (Berna, 2001).

O educador ambiental precisa ter clara compreensão dessa realidade, e deve procurar associar-se às lutas populares pelo resgate cultural, utilizando técnicas como "memória viva", para iniciar uma formação de identidade cultural dos educandos. A técnica da memória viva consiste em se lançar mão de uma pessoa de certa idade, que tenha testemunhado a existência do espaço antes mesmo que ocorresse tal degradação ambiental.

A Educação Ambiental, à medida que se torna mais política do que técnica passa também a assumir o processo de formadora da identidade política e cultural. É nesse sentido que as coisas se alinham, lutas e movimentos em defesa da cidadania. Entendendo esta última como respeito aos interesses e direitos do próximo. A Educação Ambiental deve estimular e potencializar o sentimento de poder das populações e promover oportunidades para possíveis mudanças.

\section{Programa de Educação Ambiental Proposto}

Através dessas informações e observações obtidas durante a pesquisa, que serviu de amostragem da população bonjesusense, pôde-se traçar um perfil sócio, econômico e cultural dessa população, que revela um poder aquisitivo que pode ser avaliado entre baixo e médio. Sem muitas opções, a maioria dessas famílias reside em casas humildes, e apresentam um vestuário simples, portanto, não ostentam peças caras de roupas de grife ou quaisquer tipos de riquezas.

Muitas famílias diante do contexto de que vivem, de residirem em áreas inóspitas, nos sítios, em uma área rural, além dessas dificuldades que têm esses alunos que vivem nessas áreas, quer seja no deslocamento dos sítios até a escola, ou da sua própria subsistência, encontram também dificuldades para dividir sua atenção entre a escola e o trabalho na agricultura, do qual depende toda sua família, onde muitos terminam por optar pelo trabalho. Portanto, faz-se necessário que a Educação Ambiental seja inserida e disseminada para essa comunidade carente de informações ambientais, tanto de maneira formal nas escolas como informalmente através de palestras etc. 
Diante do que foi exposto anteriormente, este artigo científico propõe o seguinte programa de educação ambiental, sugerida por Berna (2001) em seu livro "Como fazer educação ambiental: para efeito didático, a Educação Ambiental pode ser classificada em dois tipos:

a) Formal - aquela que ocorre em sala de aula, baseada na formação escolar;

b) Informal - aquela que ocorre fora da sala de aula, baseada na informação junto à comunidade.

A Companhia de Tecnologia e Saneamento Ambiental (CETESB) de São Paulo, através da cartilha "Educação e Participação", sugerem três técnicas para aplicação da Educação Ambiental, que podem ser de grande utilidade tanto dentro como fora da sala de aula. Essas três técnicas possibilitam o encontro do aluno com o meio em que vive, desenvolvendo uma postura de análise, reflexão, crítica e ação. Possibilitando ainda o contato direto com os espaços físicos. São elas:

a) Estudo do meio - consiste em colocar o aluno em contato direto e progressivo com todos os elementos do meio ambiente em que vive e atua, através de passeios ecológicos;

b) Estudo de caso - consiste em levar o aluno a pesquisar com profundidade uma situação particular que constitua a principal ameaça do meio ambiente que pertence a sua comunidade e refletir sobre ela; e.

c) Memória viva - é o resgate de imagens conservadas na memória, por meio do relato de uma pessoa idosa ou experiente, da comunidade sobre as alterações ambientais, inclusive paisagísticas, que ocorreram no lugar onde moram.

Nessas premissas entende-se que o melhor modelo para o referido município estudado é representado pelo citado nos parágrafos anteriores.

\section{CONCLUSÃO}

Dessa forma, podemos concluir que de acordo com os resultados da pesquisa e fatos observados, a solução ou a minimização das degradações ambientais existentes e a ausência das políticas públicas na cidade de Bom Jesus, estão atreladas à participação direta e consciente de toda a sua população. Pois grande parte desses problemas ambientais dessa cidade são reflexos do descaso econômico, político e social dos seus governantes.

A individualidade constatada, tanto por parte dos governantes, e como também, por parte da própria população, contribui para a esta situação de práticas de atitudes e comportamentos incorretos, que menosprezam o meio ambiente que vivem, atuando como víeis ao desenvolvimento sustentável.

A sugestão que se poderia apresentar para a solução de tais problemas sócio-ambientais seria, o desenvolvimento de uma educação ambiental iniciada na escola, e posteriormente, junto à comunidade, despertando tanto no poder público como nos moradores, o desenvolvimento de uma consciência ecológica para a preservação ambiental, o desenvolvimento do senso de responsabilidade e de atitudes ecologicamente corretas, considerando o desenvolvimento destes fatores como de vital importância para a sobrevivência da população e do nosso planeta. 
É importante citar que a política publica observada no município estudado requer mudanças severas, visto que o modelo observado só serve para aprofundar as diferenças econômicas e sociais, que aumentam a pobreza, a miséria, a fome, as doenças e o analfabetismo. Estas coisas estão também contribuindo para intensificar as degradações ambientais nos tempos atuais, em cidades interioranas do Brasil. Mas, nós podemos mudar o rumo das coisas, podemos melhorar os padrões de vida daqueles que sofrem necessidades. Infelizmente, há ainda em nossos dias, uma falta considerável de conscientização sobre a natureza.

A proposta do estudo culmina com a implantação de um projeto de Educação Ambiental, como fator reparador destas intensas degradações ambientais, em cidades interioranas do Brasil, para que por meio deste projeto, se possa dar um basta nesse processo de autodestruição. Bem como, nos conscientizar-mos da gravidade dessa situação em que se encontra o nosso planeta, a fim de que possamos obter os meios necessários para superar essa crise existencial de forma mais sustentável possível, o que se caracteriza, por isso mesmo de ser uma questão de sobrevivência.

A Educação Ambiental é necessária, nesse processo de reparação do meio ambiente para que possa fortalecer atitudes, valores e ações que sejam ambientalmente saudáveis, apoiando o desenvolvimento sustentável e, acima de tudo, conscientizando que isto é uma questão de sobrevivência. A prática científica da Educação Ambiental exige a utilização de novas tecnologias, ambientalmente saudáveis, comprometidas com o meio ambiente e procurando atender as necessidades das comunidades.

Os governos, a indústria, os sindicatos e os consumidores devem promover a compreensão do inter-relacionamento entre um meio ambiente saudável e as boas práticas empresariais, a fim de que tenhamos uma qualidade de vida compatível com as nossas necessidades, mas também com equilíbrio dos ecossistemas e em harmonia com todas as formas de vida existentes em nosso planeta. O modo como tratamos o nosso planeta hoje, com certeza serão determinantes para o futuro e a qualidade de vida das próximas gerações.

\section{REFERÊNCIAS}

BARBIERI, J. C. Desenvolvimento e meio ambiente: as estratégias de mudanças da Agenda 21. 5ạ Ed. Vozes. Petrópolis, 1997.

BARONI, M. Ambiguidades e deficiências do conceito de desenvolvimento sustentável. Revista de Administração de Empresas, FGV, n[? 32(2), p.14-24, abr/jun, 1992.

BERNA, V. Como fazer educação ambiental. São Paulo: Paulus, 2001.

BRASIL, Companhia de Tecnologia de Saneamento Ambiental do Estado de São Paulo (CETESB). Cartilha Educação e Participação. 2001.

BRASIL, Conselho Nacional do Meio Ambiente (CONAMA). Resolução 1 "Dispõe sobre os critérios básicos e diretrizes gerais para o relatório de Impacto Ambiental", 23/jan/1986.

BRASIL, Constituição da República Federativa do Brasil. Brasília, 1988.

BRASIL, Instituto Brasileiro de Geografia e Estatística (IBGE). Pesquisa de informações básicas municipais sobre meio ambiente. IBGE. Rio de Janeiro, 2011.

BRASIL, Ministério da Educação. Parâmetros Curriculares Nacionais. Brasília, 1997.p.73

BRASIL, Ministério da Educação. Parâmetros Curriculares Nacionais. Brasília, Vol.9. p.19-82, 1997.

BRASIL, Ministério do Meio Ambiente. Educação Ambiental e Política Nacional de Educação Ambiental. Lei Federal n. 9.795 de 27 de abril de 1999. Brasília, 1999.

CARVALHO, I. C. de M. Educação Ambiental: a formação do sujeito ecológico. São Paulo. Ed. Cortez, 2004.

COZETTI, N., Lixo- marca incômoda de modernidade, Revista Ecologia e Desenvolvimento, 2001. 
DIAS, G. F., Educação Ambiental: princípios e práticas. Ed. Gaia. São Paulo, 1992.

DIAS, R. Gestão ambiental: responsabilidade social e sustentabilidade. 2. ed. São Paulo: Atlas, 2011.

GIODA, A. Problemas ambientais. S. Catarina. Artigo, 2009. www.terrabrasil.org.br Acesso em 29/04/2012.

GOMES, C.A. A Educação em perspectiva sociológica. 2a Ed. EPU. São Paulo, 1998.

IBAMA, Brasília, DF.

IDEMA, Perfil do seu município. Bom Jesus - Natal, RN - 2007.

JACOBI, P. Educação Ambiental Cidadania e Sustentabilidade. Ed. Cortez. São Paulo, 2003.

LOPES, I.V. Filho, G. S. B, Biller, D. \& Bale, M. Gestão ambiental no Brasil, experiência e sucesso. Ed. Fundação Getúlio Vargas. Rio de Janeiro, 1996.

MEIRELLES, S. A. A explosão urbana - Revista Ecologia e Desenvolvimento, 2001.

MEKSENAS, P. Cidadania, Poder e Comunicação. Ed. Cortez. São Paulo, 2002.

MORIN, Edgar, Ciências com consciência. Rio de Janeiro. Ed. Bertrand Brasil, 2000.

NOVAIS, Maurício. Opulência e pobreza: causas e conseqüências da degradação sócio-ambiental. Instituto Ethos, São Paulo, 2008. www.ethos.org.br. Acesso em 29 abr.2012.

REIS, E. J. \& MOTA, R. S. The application of economic instruments in environmental policy: The Brazilian case. Revista Brasileira de Economia. Rio de Janeiro, 48(4): pp. 551-75.

SALDANHA, C. J., Sociedade, meio ambiente, políticas públicas e a erradicação de velhas práticas. Artigo. Jornal da Ciência, 13/07/2009.

SANCHEZ, L. E. Avaliação de Impacto Ambiental: conceitos e métodos. Oficina de Textos. São Paulo, 2008.

SANTOS, M. Da Totalidade do lugar. 1a Ed. Editora da Universidade de São Paulo, São Paulo, 2008.

SILVA, R. G. (1998) Manual de prevenção e combate aos incêndios florestais, Editora

SILVA-SANCHEZ, S. S. Cidadania ambiental: novos direitos no Brasil. Annablume/Humanitas. São Paulo, 2000.

VIANA Jr., A. Paper apresentado no seminário "Populações, Territórios e Recursos Naturais", Instituto de Estudos Amazônicos e Ambientais (IEA), 1994.

VININHA, F. C. Ecoturismo e Preservação ambiental. Artigo publicado em 29/jul/2004. Jornalista e Diretora da Revista Ecotour. Internet, acesso em 10/jul/2012.

WEBER, A. N. et al. Políticas Públicas em Biodiversidade: Conservação e uso Sustentado no País da Megadiversidade. Artigo Científico. 16/07/2009.

ZACARIAS, R. Consumo, lixo e educação ambiental: uma abordagem crítica. Juiz de Fora: ed. FEME, 2000. 